OPEN ACCESS

Edited by:

Nour Eissa

University of Manitoba, Canada

Reviewed by:

Erchao Li,

Hainan University, China

Jianjian $L v$,

Yellow Sea Fisheries Research

Institute (CAFS), China

${ }^{*}$ Correspondence:

Xugan Wu

wuxugan@hotmail.com

Yongxu Cheng

chengyongxucrablab@hotmail.com

Chaoshu Zeng

chaoshu.zeng@jcu.edu.au

Specialty section:

This article was submitted to

Aquatic Physiology,

a section of the journal

Frontiers in Physiology

Received: 31 October 2017 Accepted: 05 December 2017 Published: 04 January 2018

Citation:

Long X, Wu X, Zhao L, Ye H, Cheng Y and Zeng C (2018) Physiological Responses and Ovarian Development of Female Chinese Mitten Crab Eriocheir sinensis Subjected to

Different Salinity Conditions.

Front. Physiol. 8:1072.

doi: 10.3389/fphys.2017.01072

\section{Physiological Responses and Ovarian Development of Female Chinese Mitten Crab Eriocheir sinensis Subjected to Different Salinity Conditions}

\author{
Xiaowen Long ${ }^{1}$, Xugan $\mathrm{Wu}^{2,3,4 *}$, Lei Zhao ${ }^{2}$, Haihui $\mathrm{Ye}^{1}$, Yongxu Cheng ${ }^{2,3,4 *}$ and \\ Chaoshu Zeng ${ }^{1,3,5 *}$
}

${ }^{1}$ Department of Marine Biology and Technology, College of Ocean and Earth Sciences, Xiamen University, Xiamen, China, ${ }^{2}$ Centre for Research on Environmental Ecology and Fish Nutrition of Ministry of Agriculture, Shanghai Ocean University, Shanghai, China, ${ }^{3}$ Shanghai Engineering Research Center of Aquaculture, Shanghai Ocean University, Shanghai, China, ${ }^{4}$ National Demonstration Centre for Experimental Fisheries Science Education, Shanghai Ocean University, Shanghai, China, ${ }^{5}$ Centre for Sustainable Tropical Fisheries and Aquaculture, College of Marine \& Environmental Sciences, James Cook University, Townsville, QLD, Australia

Salinity plays a key role affecting ovarian development, osmoregulation and metabolism of female Chinese mitten crab, Eriocheir sinensis during reproductive migration. In this study, female E. sinensis after their puberty molt were subjected to four salinities of $0,6,12$, and $18 \%$ for 40 days to investigate the salinity effects on their ovarian development as well as a range of important physiological parameters. Elevated salinity accelerated the ovarian development with ovigerous crabs found at salinity treatments of 12 and $18 \%$ despite no copulation had occurred. Meanwhile the survival rate of female crabs showed a decreasing trend with increasing salinity. Higher salinity also led to increased hemolymph $\mathrm{Na}^{+}, \mathrm{K}^{+}, \mathrm{Ca}^{2+}, \mathrm{Cl}^{-}$, and $\mathrm{Mg}^{2+}$ concentrations. The $6 \%$ treatment had the highest contents of hemolymph total and major free amino acids while the $\mathrm{Na}^{+} / \mathrm{K}^{+}$-ATPase activity in the posterior gills was the lowest among treatments. Total $n-3$ polyunsaturated fatty acids ( $\sum n-3 P U F A$ ) and n-3/n-6 PUFA ratio in the anterior gills showed a decreasing trend with salinity while $18 \%$ had the highest $\sum$ PUFA and $\sum n-6 P U F A$. The $\sum n-3 P U F A$ content and n-3/n-6 PUFA ratio of the posterior gills showed a fluctuating pattern and the highest value was detected at $0 \%$, while an increasing trend was found for the $\sum n$-6PUFA with increasing salinity. The hemolymph glucose showed a decreasing trend with increasing salinity and the highest total cholesterol in hemolymph was detected at $12 \%$. The $18 \%$ treatment had the highest levels of hemolymph $\gamma$-glutamyltransferase, alkaline phosphatase and acid phosphatase, as well as glucose, urea and acid phosphatase in hepatopancreas while the highest hemolymph superoxide dismutase and malondialdehyde were detected at $0 \%$. Overall, the results showed that salinity increase from freshwater to brackish conditions led to lower metabolism, accelerated ovarian development, and the appearance of ovigerous crabs without copulation in female $E$. sinensis post puberty molt.

Keywords: Eriocheir sinensis, females, salinity, ovarian development, physiological responses 


\section{INTRODUCTION}

The Chinese mitten crab, Eriocheir sinensis, earned its name from the distinguishing feature of dense patches of hairs on its chelipeds. The freshwater crab species is native to China and is distributed widely in streams and rivers along the eastern coasts of China (Sui et al., 2009; Zeng et al., 2012). The species has also been introduced to Europe and America and has become established locally, which is considered as an invasive species (Anger, 1991; ref for American case). The Chinese mitten crab spends most of its live in freshwater, but after puberty molt, sexual mature crabs migrate downstream to estuaries for reproduction (Zhang et al., 2001; Cheng et al., 2008). During the reproductive migration, the gonads of the crabs gradually develop and finally reach mature after arriving in the estuaries where they copulate and spawn (Zhang, 1973; Bentley, 2011). Salinity is hence considered a key environmental factor that affects gonadal development, reproduction and physiological status of sexual mature E. sinensis. It is well-known salinity in estuaries fluctuates substantially due to tides and freshwater runoff from rivers and streams (Wang and Xu, 2003); indeed, salinity of Yangtze River estuaries, where E. sinensis migrate to for reproduction, reportedly fluctuates between 3.4 and 17\%o (Zhang, 1973; Zhang and $\mathrm{Li}, 2002$ ). Due to changes in salinity condition during the reproductive migration, as E. sinensis migrating toward estuaries, osmoregulatory mechanisms are expected to be mobilized to cope with such change (Wang and Xu, 2003; Jia et al., 2012).

E. sinensis is known as a euryhaline species and a strong osmoregulator (Rathmayer and Siebers, 2001; Wang et al., 2012). It is well-documented that various ions and free amino acids are the main contributors to hemolymph osmolality of crustaceans; as facilitated by various ion transport enzymes and proteins, they play crucial roles in crustacean osmoregulation (Towle and Weihrauch, 2001; Romano and Zeng, 2012). Among the ion transportation enzymes and proteins, $\mathrm{Na}^{+} / \mathrm{K}^{+}$-ATPase in the posterior gills of crustaceans is well-known highly important (Genovese et al., 2004; Cieluch et al., 2007).

Past studies on effects of salinity on E. sinensis have mostly focused on either a single aspect of physiological change and/or over short-term exposure (Wang and Xu, 2003; Lu et al., 2011; Jia et al., 2012). To date, there is a lack of comprehensive study on osmoregulation and physiological responses of E. sinensis exposed to different salinity conditions, particularly in the case of long-term exposure. Moreover, while it has been shown that brackish water (15\%) promoted gonadal development of E. sinensis following puberty molting (Wu et al., 2013), it is unclear whether and how effects of salinity on gonadal development of $E$. sinensis are correlated with other important physiological processes, such as osmoregulation and metabolism.

Previous studies have also shown clear gender differences in the onset of reproductive migration of E. sinensis, for example, the arriving time in estuaries is different between males and females. The female crabs generally start reproductive migration earlier and arrive in estuaries first where they wait for males to arrive during the time their ovaries further mature; once males arrive in estuaries, copulation occurs before they depart again and the females move further downstream to spawn and hatch larvae (Lai, 1994; Zhang and Li, 2002; Bentley, 2011). As such, there are likely gender differences in physiological responses to salinity changes during reproductive migration and gonadal development, which necessitates studies on salinity effects on gonadal development of E. sinensis being carried out separately for males and females. Our recent studies have reported the effects of long-term salinity adaptation on gonadal development, osmoregulation and metabolism of adult male E. sinensis (Long et al., 2017b), however it remains unknown the physiological responses and ovarian development of female E. sinensis subjected to different salinity conditions. Therefore, the present study comprehensively investigated the effects of long-term exposure to different salinities on ovarian development, hemolymph osmolality and major ion as well as free amino acid concentrations, gill $\mathrm{Na}^{+} / \mathrm{K}^{+}$-ATPase activity and fatty acids profile, as well as a range of metabolic and antioxidant indices in hemolymph and hepatopancreas of the female E. sinensis following puberty molt.

\section{MATERIALS AND METHODS}

\section{Experimental Design and Set Up}

Female E. sinensis used for the experiments were obtained from a crab farm in Yangchenghu Lake, Jiangsu province, China in early October, 2013 following their puberty molt. They were transported to Fengxian aquaculture research center, Shanghai Fisheries Research Institute, Shanghai, China, where the salinity experiment was conducted. Only active and appendage intact females were selected and randomly stocked into 8 indoor polyethylene tanks (length $\times$ width $\times$ depth $=2.5 \times 3.75 \times$ $1.0 \mathrm{~m}$ ) for the experiment. To confirm gonadal development status of the crabs, at the beginning of the experiment, 15 females were randomly selected and dissected to obtain ovaries. The ovaries from each crab were subsequently weighed to calculate gonadosomatic index (GSI). With the mean GSI of the sampled crabs at only $3.78 \pm 0.64 \%$, the results confirmed that these crabs had similar immature gonads. The initial body weight (BW) of the female crabs ranged from 100 to $120 \mathrm{~g}$. Approximately $40 \%$ bottom area of the tanks was covered by $10-20 \mathrm{~cm}$ fine sand and pieces of polyvinyl chloride (PVC) tubes (diameter: $15 \mathrm{~cm}$ ) and tiles were provided as shelters for crabs. Four salinity treatments, $0,6,12$, and $18 \%$, were set up, and each treatment had two replicate tanks with 30 crabs stocked in a tank. During the experiment, water depth of each tank was maintained at $70 \mathrm{~cm}$. The initially salinity in all tanks was $0 \%$, following the stocking of the crabs, salinity in the tanks allocated for higher salinity treatments was gradually increased to the designated levels, respectively at a rate of $3 \%$ day ${ }^{-1}$ by adding brine.

The experiment started on 11th October, 2013 and lasted for 40 days. During the experiment, the crabs were fed daily at 18: 00 with trash fish and residue of the feed was removed next morning. The feeding ration was adjusted based on water temperature and leftover food during the experiment, i.e., 3-5\% total biomass when water temperature $>20^{\circ} \mathrm{C}$ but reduced to $1-$ $3 \%$ of total biomass at $15-20^{\circ} \mathrm{C}$. Throughout the experiment, all rearing tanks were aerated and photoperiod was set at $12 \mathrm{~h}$ light: $12 \mathrm{~h}$ dark with fluorescent lamps $(40 \mathrm{~W})$ as the lighting 
source. The water temperature in each tank was measured daily at 12:00 and 22:00, and ammonia- $\mathrm{N}$, nitrite, dissolved oxygen (DO) and $\mathrm{pH}$ were measured every 3 days. Water in each tank was exchanged based on water parameter readings in order to keep water quality parameters within following ranges: ammonia$\mathrm{N}<0.5 \mathrm{mg} \mathrm{L}^{-1}$; nitrite $<0.15 \mathrm{mg} \mathrm{L}^{-1} ; \mathrm{DO}>4 \mathrm{mg} \mathrm{L}^{-1}$ and $\mathrm{pH}$ 7.0-8.5 throughout the experiment.

\section{Sampling Procedure}

All crabs were starved for $24 \mathrm{~h}$ prior to sampling on day 40 . Four crabs were randomly sampled from each tank and their weights measured using a digital balance (precision: $0.01 \mathrm{~g}$ ). All crabs were treated with cold shock method to minimize suffering, then around $2 \mathrm{~mL}$ hemolymph was withdrawn from each crab sample by inserting a $1.0 \mathrm{~mL}$ syringe at the base of the third walking leg and all hemolymph samples were stored at $-40^{\circ} \mathrm{C}$ for later analysis. It is known that E. sinensis has six pairs of gills, previous studies have shown that the first 3 pairs of the gills (pairs 1-3, also known as anterior gills) are responsible for respiration while pairs 4-6 of gills (posterior gills) are specified for osmoregulation (Long et al., 2017b). Therefore, in this study, the pairs 5 posterior gills were sampled and snap frozen in liquid nitrogen and stored at $-80^{\circ} \mathrm{C}$ for the $\mathrm{Na}^{+} / \mathrm{K}^{+}$-ATPase activity and its mRNA expression analysis. The remaining anterior and posterior gills were stored at $-40^{\circ} \mathrm{C}$ for later fatty acid analysis. The ovary and hepatopancrea of each crab were also dissected and their weight measured before being stored at $-40^{\circ} \mathrm{C}$ for various biochemical analysis.

Based on the ovarian and hepatopancreas weights obtained, the gonadosomatic index (GSI) and hepatosomatic index (HSI) of each crab were calculated using following formulas:

$$
\begin{aligned}
G S I & =\frac{M_{G}}{M_{C}} \times 100 \% \\
H S I & =\frac{M_{H}}{M_{C}} \times 100 \%
\end{aligned}
$$

where $M_{G}$ is gonad weight, $M_{H}$ is hepatopancreas weight and $M_{C}$ is crab weight.

\section{Hemolymph Osmolality and Ionic Concentrations}

The hemolymph samples were firstly thawed and homogenized using an IKA homogenizer (T10B, IKA Co., Germany). The resultant homogenates were then centrifuged at $10,000 \times \mathrm{g}$ for $20 \mathrm{~min}$ at $4^{\circ} \mathrm{C}$, and the supernatant was collected for analysis. The hemolymph osmolality was analyzed using a freezing-point osmometer (OSMOMAT 030, Gonotec, Berlin, Germany). The concentrations of $\mathrm{Na}^{+}, \mathrm{K}^{+}, \mathrm{Ca}^{2+}$, and $\mathrm{Cl}^{-}$were detected using an electrolyte analyzer (K-Lite 5, Meizhou Kangli high-tech Co., Ltd, Guangzhou, China), while the concentration of $\mathrm{Mg}^{2+}$ was determined with a spectrophotometer (T6 New Century, Beijing Purkinje General Instrument Co., Ltd, Beijing, China) and a commercial test kit (Nanjing Jiancheng Bioengineering Institute, Nanjing, China).

\section{Free Amino Acids in Hemolymph}

Each hemolymph sample was de-proteinized by adding an equal volume of $12 \%$ (m: v) trichloroacetic acid (TCA) (Chew et al., 1999) and subsequently vibrated using SCILOGEX MX-S vortex mixer (SCILOGEX, LLC, Berlin, CT, USA) before being placed in $4^{\circ} \mathrm{C}$ freezer for $20 \mathrm{~min}$. The mixture was then centrifuged at $10,000 \times \mathrm{g}$ and $4^{\circ} \mathrm{C}$ for $10 \mathrm{~min}$ using an Eppendorf centrifuge (5417R, Eppendorf, Hamburg, Germany). The supernatant was collected and $\mathrm{pH}$ adjusted to 2.2 by adding $6 \mathrm{M} \mathrm{NaOH}$ solution. The analysis of free amino acids (FAAs) was performed with a Hitachi L-8900 Amino Acid Analyzer (Hitachi, Ltd., Tokyo, Japan) with a Li column (Inter diameter $\times$ length $=4.6 \times$ $60 \mathrm{~mm}$ ), which packed with Hitachi custom ion exchange resin \#2622 (Particle size: $3 \mu \mathrm{m}$ ).

\section{Gill $\mathrm{Na}^{+} / \mathrm{K}^{+}$-ATPase Activity and mRNA Expression}

Approximately $0.2 \mathrm{~g}$ posterior gill from each crab was homogenized in $1 \mathrm{~mL}$ ice-cold homogenization buffer $\left[1 \mathrm{~mol} \mathrm{~L}^{-1}\right.$ Tris- $\mathrm{HCl}(\mathrm{pH}=7.6): 10 \mathrm{~mL} ; \mathrm{NaCl}: 2.925 \mathrm{~g} ;$ EDTA: $0.05 \mathrm{~g}$; $100 \mathrm{mmol} \mathrm{L}{ }^{-1}$ PMSF: $0.5 \mathrm{~mL}$; and dilute to $500 \mathrm{~mL}$ with distilled water] using IKA homogenizer (T10B, IKA Co., Germany). The homogenate was centrifuged at $10,000 \times \mathrm{g}$ for $10 \mathrm{~min}$ at $4^{\circ} \mathrm{C}$, and the supernatant was collected for subsequent analysis (Long et al., 2017b). The $\mathrm{Na}^{+} / \mathrm{K}^{+}$-ATPase activity and total soluble protein in the supernatant were determined with a spectrophotometer (T6 New Century, Beijing Purkinje General Instrument Co., Ltd, Beijing, China) at 540 and $595 \mathrm{~nm}$ absorbance, respectively, and the assays were performed using respective commercial assay kits (Nanjing Jiancheng Bioengineering Institute, Jiangsu, China) according to manufacture's instruction.

For measuring mRNA expression level of $\mathrm{Na}^{+} / \mathrm{K}^{+}$-ATPase, the frozen posterior gills were grounded in a mortar with liquid nitrogen, and then total RNA was isolated using a RNA extracting kit (Cat. D9108A, Takara Biotechology Co., Ltd., Dalian, China) following the manufacture's protocol. The final total RNA was dissolved in $200 \mathrm{~mL}$ RNase-free water. The concentration of total RNA was determined using a NanoDrop 2000 spectrophotometer (Thermo, Scientific, USA) and the RNA integrity was checked with $1 \%$ agarose gel electrophoresis. One hundred ng of total RNA was subsequently used as reverse-transcription template for the synthesis of first strand cDNA using a reverse transcription kit (Cat.D2639A, Takara Biotechology Co., Ltd., Dalian, China). According to $\mathrm{Na}^{+} / \mathrm{K}^{+}$ATPase gene sequence of $E$. sinensis, specific primers were designed by Primer Premier 5.0 software, and the sequence was shown in Table 1. The $\beta$-actin gene of E. sinensis was used as a reference gene.

\section{Gill Fatty Acid Profile}

The anterior and posterior gills of crabs from each experimental tank were pooled, homogenized and freeze-dried, respectively. Total lipids in the gill samples were extracted based on the method of (Folch et al., 1957)Fatty acid methyl esters (FAMEs) were prepared by boiling $14 \%$ boron trifluoride/methanol (w/w) (Morrison and Smith, 1964). FAMEs were analyzed by flame ionization detection (FID) after injecting a sample into a 
Thermo Trace GC Ultra gas chromatograph fitted with a $100 \times$ $0.25 \mathrm{~mm}$ ID $(0.2 \mu \mathrm{m}$ film thickness) Supelco SP-2560 capillary column (Supelco, Inc., Billefonte, PA, USA). Injector and detector temperatures were $260^{\circ} \mathrm{C}$. The column temperature was initially held at $70^{\circ} \mathrm{C}$, followed by an increase at a rate of $50^{\circ} \mathrm{C} \mathrm{min}^{-1}$ to $140^{\circ} \mathrm{C}$ and held for $1 \mathrm{~min}$, then increase to $180^{\circ} \mathrm{C}$ at $4^{\circ} \mathrm{C} \mathrm{min}{ }^{-1}$ and held for $1 \mathrm{~min}$. It was then further increased at $3^{\circ} \mathrm{C} \mathrm{min}{ }^{-1}$ to the final temperature of $225^{\circ} \mathrm{C}$ and held for $30 \mathrm{~min}$ until all FAMEs had been eluted. The carrier gas was nitrogen with the flow velocity at $1 \mathrm{~mL} \mathrm{~min}^{-1}$. Peaks were identified by comparing retention times with known standard (Sigma-Aldrich Co., St. Louis, MO, USA). Fatty acid profile was expressed as percentage of each fatty acid to the total fatty acids (\% total fatty acids) based on the area percentage.

\section{Other Biochemical Parameters in Hemolymph and Hepatopancreas}

Approximately $0.2 \mathrm{~g}$ hepatopancreas tissue from each crab was homogenized in $1 \mathrm{~mL}$ icy physiological saline $\left[210 \mathrm{mmol} \mathrm{L}^{-1}\right.$ $\mathrm{NaCl} ; 13.6 \mathrm{mmol} \mathrm{L}{ }^{-1} \mathrm{KCl} ; 3.8 \mathrm{mmol} \mathrm{L}^{-1} \mathrm{MgCl}_{2} ; 2.6 \mathrm{mmol} \mathrm{L}^{-1}$ $\mathrm{Na}_{2} \mathrm{SO}_{4} ; 10 \mathrm{mmol} \mathrm{L}^{-1}$ Hepse (pH 7.5)] with an IKA homogenizer (T10B, IKA Co., Germany). The homogenate was centrifuged at $10,000 \times \mathrm{g}$ for $20 \mathrm{~min}$ at $4^{\circ} \mathrm{C}$ and the supernatant was collected for subsequent analysis. Similarly, the hemolymph samples were firstly thawed, subsequently homogenized and centrifuged by the same procedure, and the supernatant was collected for later biochemical analysis.

The total cholesterol, triglyceride, high-density lipoprotein cholesterol, low-density lipoprotein cholesterol, uric acid, urea, glucose, alkaline phosphatase, and $\gamma$-glutamyltranspeptidase were analyzed using an automatic biochemical analyzer (BS-200, Shenzhen Mindray Bio-Medical Electronics Co., Ltd., China) and commercial bio-kits (Shanghai Jinxi Biotech Co., Ltd, Shanghai, China). The activity of superoxide dismutase and acid phosphatase was detected according to (Qiu et al., 2011) and Feng et al. (2013), while the malonaldehyde was determined by the thiobarbituric acid method (Ohkawa et al., 1979) using a commercial kit (Nanjing Jiancheng Bioengineering Institute, Jiangsu, China).

\section{Statistical Analysis}

Data are presented as mean \pm standard error (SE). Homogeneity of variance was tested with Levene's test. When necessary, arcsine-square root of logarithmic transformation was performed

TABLE 1 | Primers for quantitative real-time PCR of $\mathrm{Na}^{+} / \mathrm{K}^{+}$-ATPase $\alpha 1$ gene of female $E$. sinensis.

\begin{tabular}{lll}
\hline Primer & Sequence $\left(\mathbf{5}^{\prime}-\mathbf{3}^{\prime}\right)$ & $\begin{array}{l}\text { NCBI accession number } \\
\text { or reference }\end{array}$ \\
\hline NAK-RT F & TGAATGACTCCCCAGCTCTCAAGA & AF3011581.1 \\
NAK-RT R & CAGAATCATGTCAGCAGCCTGCTT & \\
$\beta$-actin 1F & TCATCACCATCGGCAATGA & Guo et al., 2013 \\
$\beta$-actin 1 R & TTGTAAGTGGTCTCGTGGATG & HM053699.1
\end{tabular}

Note that this table cited in the previously published article by Long et al. (2017b). prior to analysis. Statistical analyses were conducted using oneway ANOVA and compared with Duncan's multiple range test. $P<0.05$ was regard as statistically significant difference. All statistical analysis was performed using SPSS package (version 16.0).

\section{RESULTS}

\section{Survival, GSI, and HSI}

The survival rates of the crabs in all four salinity treatments initially remained high and similar during the first 20 days but showed a more substantial decline from day 25 onward, particularly for the highest salinity treatment $(18 \% 0)$. By the end of the experiment (day 40), crab survival showed a trend of decrease with increasing salinity, ranged from $61.3 \%$ of the $18 \%$ treatment to $90.0 \%$ of the $0 \%$ o treatment (Figure 1). The differences of the final survival among treatments are statistically significant $(P<0.05)$.

The gonadosomatic index (GSI) of female E. sinensis showed a clear increasing trend with increasing salinity (Figure 2A) and the crabs from the highest salinity $18 \%$ o treatment had significant higher GSI than other treatments $(P<0.05)$ except the $12 \%$ o treatment. No significant difference was detected among the other three lower salinity treatments $(P>0.05)$.

The hepatosomatic index (HSI) showed a pattern of initially increased with salinity from 0 and $6 \%$, but subsequently decreased as salinity increased further to $18 \%$, resulting in the highest and the lowest HSI obtained from the 6 and $18 \%$ treatments, respectively, and a significant difference between the two treatments $(P<0.05$, Figure 2B).

Interestingly, egg carrying female crab was found without copulation in both the 12 and $18 \%$ o treatments. By the end of the experiment on the day 40 , the numbers of such ovigerous females in both treatments were substantial although the $18 \%$ o treatment had significantly higher percentage $(35.0 \%)$ than that of the $12 \%$ o treatment $(26.7 \%)(P<0.05$, Figure 3$)$. No ovigerous crabs were found throughout the experiment in the other two lower salinity treatments (Figure 3). Microscopic examination

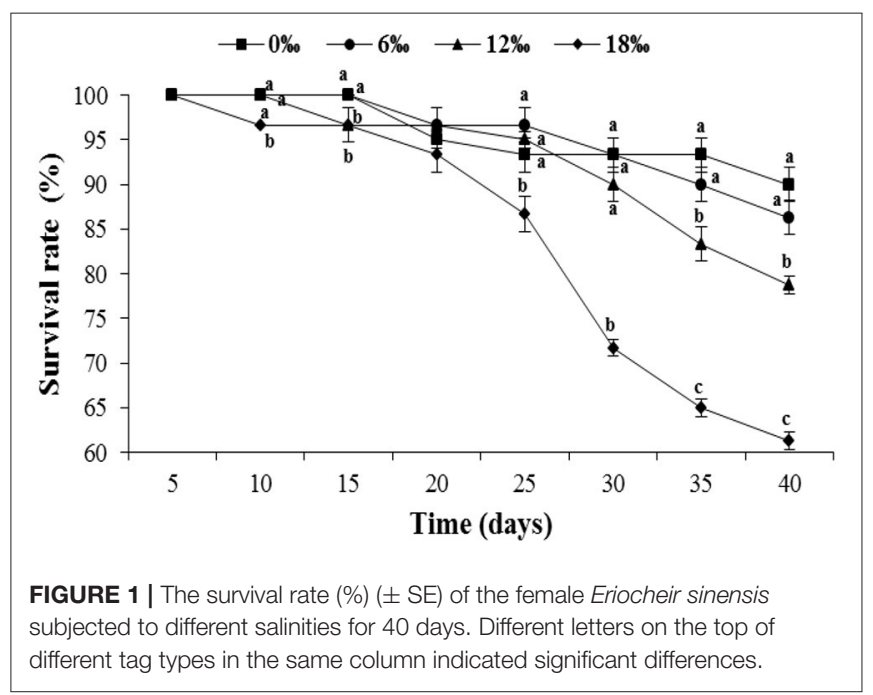



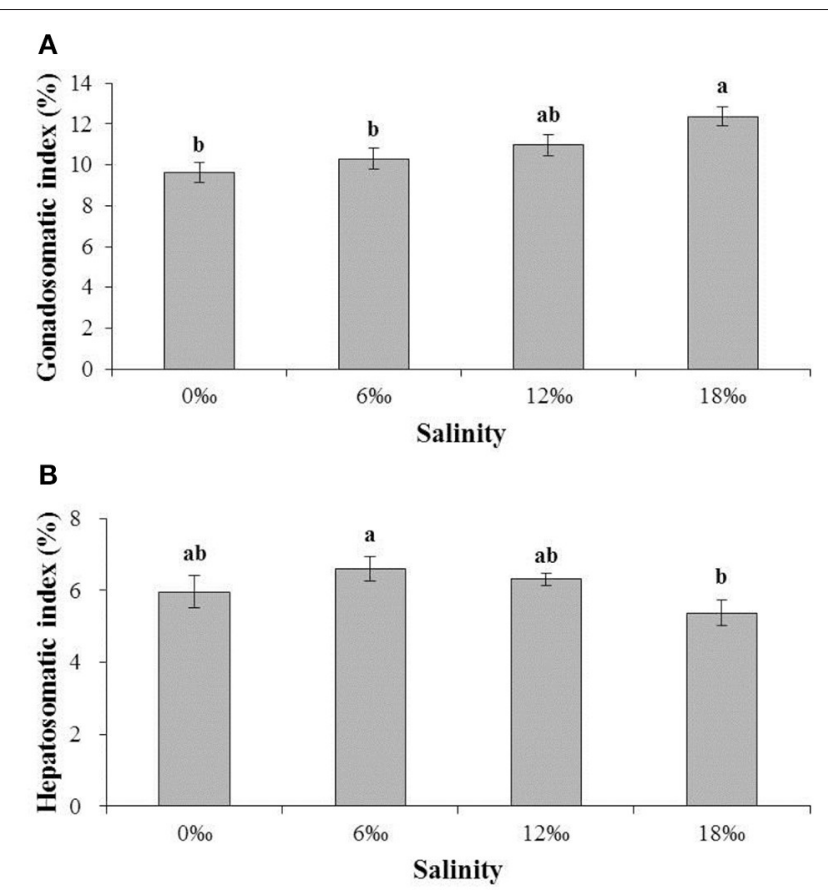

FIGURE 2 | The gonadsomatic index (GSI) (\%) and hepatosomatic index (HSI) (\%) ( $\pm \mathrm{SE}$ ) of the female $E$. sinensis subjected to different salinities for 40 days. (A): GSI; (B): HSI. Different letters on the tops of the bars indicated significant differences.

of the spermathecaes of the ovigerous female crabs found no spermatophore within, confirming that the egg carrying female crabs in this study were indeed not copulated. Additionally, it was observed that all unfertilized eggs initially attached to ovigerous crabs failed to develop further and eventually dropped off within 2-3 days.

\section{Hemolymph Osmolality, Ionic Concentrations, and Free Amino Acid Composition}

Hemolymph osmolality showed a trend of decrease initially (a minimum detected at $6 \%$ ) but subsequently increased as salinity increased from 0 to $18 \%$, however no significant difference was detected among all treatments $(P<0.05$, Figure 4A). Of five major ions $\left(\mathrm{Na}^{+}, \mathrm{K}^{+}, \mathrm{Ca}^{2+}, \mathrm{Cl}^{-}\right.$, and $\left.\mathrm{Mg}^{2+}\right)$ measured, all showed an overall increasing trend with increasing salinity $(P<0.05)$, and except $\mathrm{Mg}^{2+}$, the concentrations of the other four ions were always higher in the hemolymph than in the external media (Figures 4B-F).

Table 2 shows results of hemolymph free amino acid analysis. The total free amino acids (TFAAs) increased sharply with the increase of salinity from $0 \%$ o $\left(2500.60 \pm 101.98 \mathrm{nmol} \mathrm{mL}^{-1}\right)$ to $6 \%$ o $\left(3238.10 \pm 41.70 \mathrm{nmol} \mathrm{mL}^{-1}\right)$ but subsequently decreased as salinity further increased to $12 \%$ (2686.50 \pm 116.63 $\left.\mathrm{nmol} \mathrm{mL} \mathrm{m}^{-1}\right)$ and $18 \%$ o $\left(2594.30 \pm 145.71 \mathrm{nmol} \mathrm{mL}^{-1}\right)$. This resulted in $6 \%$ salinity treatment had significant higher TFAAs $(P<0.05)$ as well as the highest contents of major amino acids, including asparagine, glutamine, proline, alanine, citrulline,

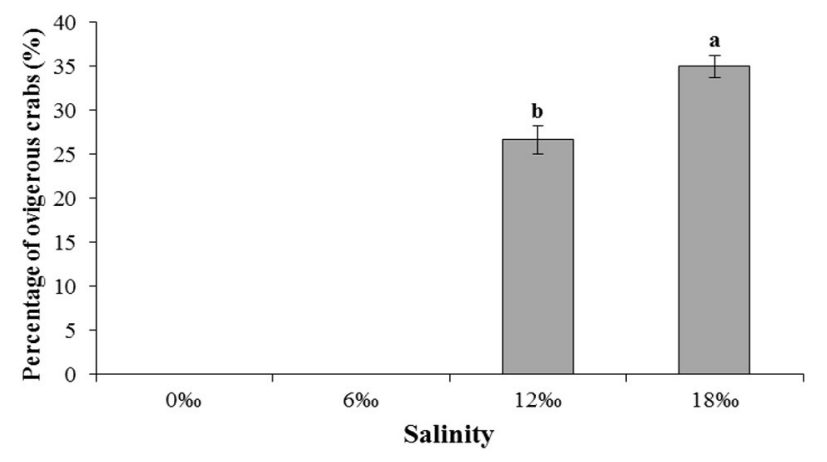

FIGURE 3 | The percentage (\%) ( \pm SE) of vigorous female E. sinensis subjected to different salinities over 40 days. Different letters on the tops of the bars indicated significant differences.

valine, methionine, isoleucine, leucine, phenylalanine, $\beta$-alanine, lysine, histidine and arginine. The most important contributors to TFAAs ( $>100 \mathrm{nmol} \mathrm{mL}^{-1}$ ), listed in the following on sequence of their relatively important, are: proline, alanine, taurine, arginine, glycine, and glutamine. Among these FAAs, proline, alanine, arginine and glutamine were the highest at $6 \%$ and significantly higher than other salinity treatments except alanine $(P<0.05)$. The alanine and glycine were not significantly different among all treatments while taurine increased with salinity to reach a peak at $12 \%$ out decreased at $18 \%$ o $(P<0.05)$

(Table 2).

\section{Gill $\mathrm{Na}^{+} / \mathrm{K}^{+}-$ATPase and Its mRNA Expression}

The activity of $\mathrm{Na}^{+} / \mathrm{K}^{+}$-ATPase in the posterior gills decreased significantly with salinity increased from 0 to $6 \%$ but started to increase as salinity further increased to 12 and $18 \%$, resulting in the lowest $\mathrm{Na}^{+} / \mathrm{K}^{+}$-ATPase activity being recorded at $6 \%$, which was significantly lower than all other salinity treatments except the $12 \%$ o treatment $(P<0.05$, Figure 5). The expression level of $\mathrm{Na}^{+} / \mathrm{K}^{+}$-ATPase mRNA in the posterior gills showed a fluctuating pattern with the highest and the lowest level detected at 12 and $6 \%$, respectively $(P<0.05)$ (Figure 5).

\section{Gill Fatty Acids Profile}

The fatty acids profile in the anterior gills is shown in Table 3. The highest percentages of major saturated fatty acids (SFAs) and total saturated fatty acids ( $\sum$ SFA) were detected at $12 \%$ $(P<0.05)$. For monounsaturated fatty acids (MUFAs), the levels of C18:1n7, C20:1n7 and total monounsaturated fatty acids ( $\sum$ MUFA) firstly increased significantly with salinity to reach a peak at $6 \%$ but then decreased significantly with further increase in salinity $(P<0.05)$. As to polyunsaturated fatty acids (PUFAs), the $C 18: 2 \mathrm{n} 6, \mathrm{C} 20: 3 \mathrm{n} 6, \mathrm{C} 20: 4 \mathrm{n} 6$ and total n-6 polyunsaturated fatty acids ( $\sum n-6$ PUFA) showed a fluctuating pattern with the highest values detected at $18 \%$ o $(P<0.05)$. On the other hand, the C18:3n3 increased significantly with salinity initially to reach a peak at $12 \%$ before it decreased significantly at $18 \%$ o $(P<0.05)$. The C20:2n6, $\sum$ PUFA and total highly unsaturated fatty acids ( $\sum$ HUFA) firstly showed a decreasing trend with increasing 


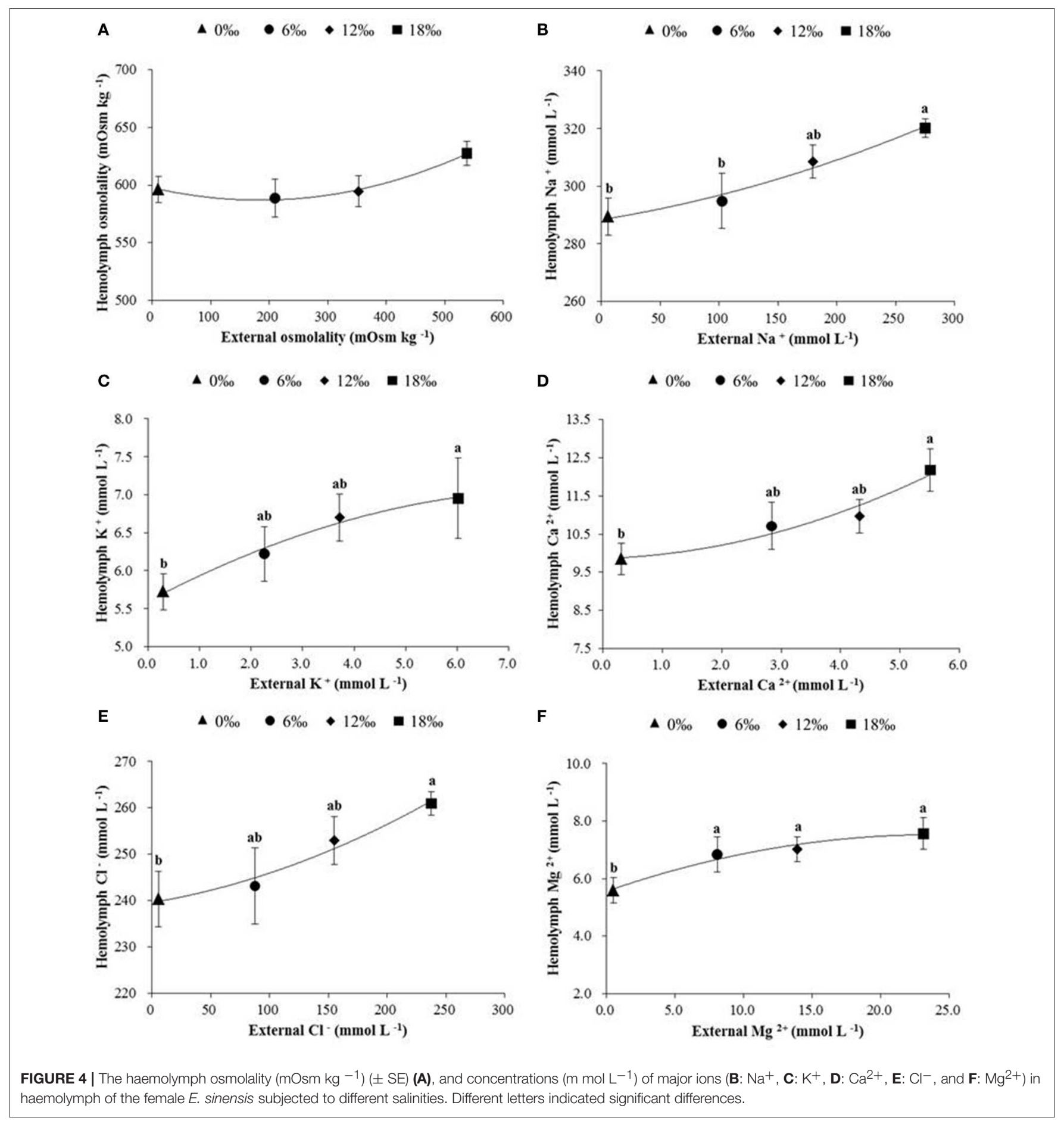

salinity with a minimum detected for $12 \%$ o treatment before it increased as salinity increased to $18 \%$ o $(P<0.05)$. Meanwhile, the highest C22:6n3 was detected at 6\%o while the $\sum n-3$ PUFA and n-3/n-6 PUFA ratio showed a decreasing trend with increasing salinity $(P<0.05)$.

In the case of posterior gills, the percentages of most major SFAs increased significantly with salinity to reach a peak at $12 \%$ o $(P<0.05)$ before decreased at $18 \%$, on the other hand, the highest $\mathrm{C} 16: 0$ and $\sum$ SFA was detected at $6 \%$ treatment
$(P<0.05)$ (Table 4). For MUFAs, the $6 \%$ treatment resulted in the highest levels of C16:1n7, C18:1n9, C18:1n7 and $\sum$ MUFA $(P<0.05)$. Regarding PUFAs, the percentage of C18:2n 6 showed a fluctuating pattern with the highest value detected at $6 \%$, while the C18:3n3 increased significantly with salinity to reach a peak at $12 \%$ before decreased significantly at $18 \%$ o $(P<0.05)$. The $0 \%$ treatment resulted in the highest percentages of C20:2n6, C20:5n3, n-3PUFA as well as n-3/n-6 ratio, while the C20:3n6 and C20:4n6 increased significantly with increasing salinity 
TABLE 2 | Free amino acids composition (nmol $\mathrm{mL}^{-1}$ ) in hemolymph of female $E$. sinensis subjected to different salinities for 40 days.

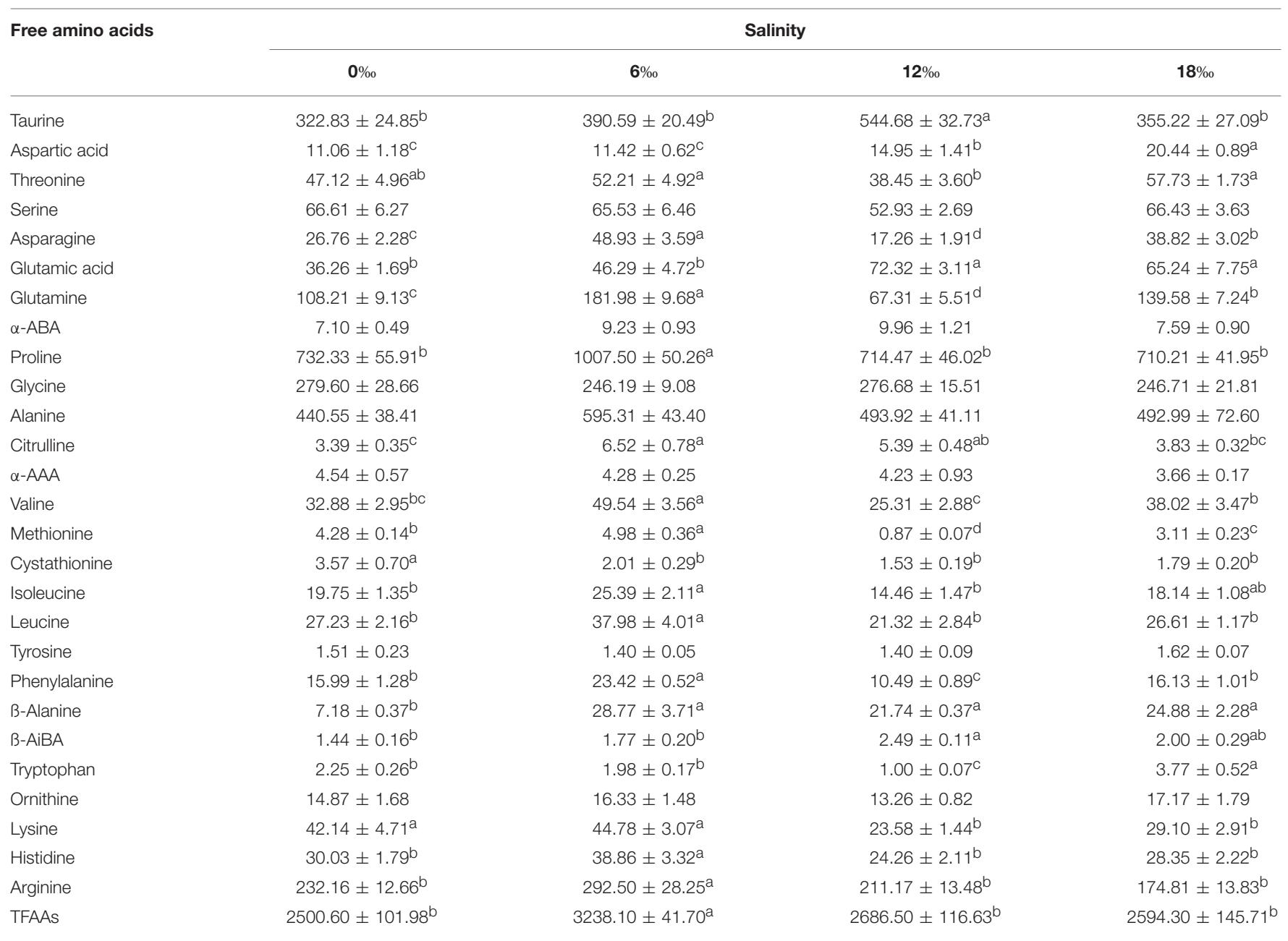

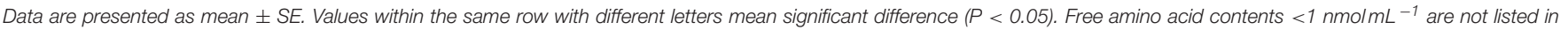
this table. $\alpha$-ABA: $\alpha$ - amino-n-butyric acid; $\alpha$-AAA: $\alpha$-aminoadipicacid; $B$-AiBA: $\beta$-aminoisobutyric acid; TFAAs: total free amino acids.

$(P<0.05)$. The C22:6n3, $\sum$ PUFA and $\sum$ HUFA showed a trend of initially decreased (a minimum detected at $6 \%$ ) but then increased with increasing salinity, while $\sum \mathrm{n}-6$ PUFA showed an overall increasing trend with increasing salinity $(P<0.05)$ (Table 4).

\section{Hemolymph and Hepatopancreas Metabolism Indices}

Various metabolism indices measured in hemolymph showed that GLU generally decreased with increasing salinity and was significantly lower at 12 and $18 \%$ while the highest content of TC was detected at $12 \%$ o $(P<0.05$, Table 5). No significant differences were detected among four salinity treatments for TG, HDL-C, LDL-C, UA and urea in hemolymph $(P>0.05)$. The levels of SOD, MDA and $\gamma$-GT showed a fluctuating pattern, but the highest and the lowest contents of all these indices were consistently found at 0 and $6 \%$, respectively. On the other hand, the highest activities of ALP and ACP were detected at $18 \%$ $(P<0.05)$.
Table 6 showed metabolism indices measured in hepatopancreas of the female crabs from different salinity treatments. The GLU content as well as the activities of ALP and ACP showed a same pattern of firstly decreased with salinity with the lowest values recorded at $6 \%$ but increased subsequently with increasing salinity $(P<0.05)$. No significant differences were detected for the contents of UA and MDA as well as the activity of SOD among all treatments $(P>0.05)$. The activity of $\gamma$-GT decreased consistently with increasing salinity $(P<0.05)$ while urea showed a fluctuating pattern with the highest level detected at $18 \%$ o $(P<0.05)$.

\section{DISCUSSION}

Salinity is a key environmental parameter that affects the survival, gonadal development and reproduction of the catadromous E. sinensis (Zhang et al., 2001; Cheng et al., 2008; Wu et al., 2013). In the current study, the female E. sinensis subjected to four salinity conditions ranging from 0 to $18 \%$ showed 
mortality mainly after day 20, and higher mortalities were found at higher salinity treatments (12 and18\%o). This may be explained by the observation that under higher salinities, female E. sinensis generally showed substantial higher level

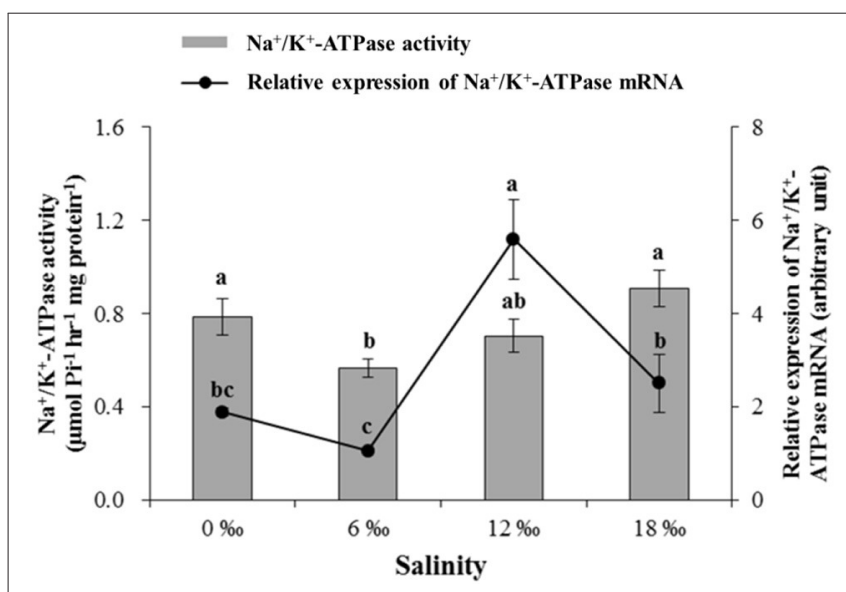

FIGURE 5 | The gill $\mathrm{Na}^{+} / \mathrm{K}^{+}$-ATPase activity ( $\mu \mathrm{mol} \mathrm{Pi} \mathrm{h}^{-1} \mathrm{mg}$ protein ${ }^{-1}$ ) and its $\mathrm{mRNA}$ expression level ( $\pm \mathrm{SE}$ ) in the posterior gills of the female $E$. sinensis subjected to different salinities for 40 days. of activity (Zhuang et al., 2012), which may lead to higher incidences of aggressive encounters, injuries and cannibalism, particularly when only females were used and kept together in a confined area such as in the current study. In fact, the GSI of the female E. sinensis from the highest salinity treatment $(18 \%$ ) was significantly higher than those form lower salinity treatments (0 and 6\%o), which suggests that the higher salinity condition in the former accelerated ovarian development of female E. sinensis. Similar results were found for male E. sinensis form a previous study by the authors (Long et al., 2017b). Such advanced gonad development under higher salinities probably triggered increased activities of the females in searching of mating males. The accelerated ovarian development under higher salinities might be explained by: (1) the osmolality of higher salinity water is closer to that of the hemolymph of the female E. sinensis, the crabs hence could have reduced energy expenditure on osmoregulation (Lee and Chen, 2003; Jia et al., 2012) while channeled more nutrients/energy to ovarian development (Wu et al., 2013); (2) elevating salinity increased hemolymph ion concentrations, which included calcium while calcium is known to have the function of promoting synthesis and absorption of vitellogenin in crustaceans (Quinito et al., 1989; Wei et al., 2005, 2007); (3) higher salinity brackish water may lead to improved

TABLE 3 | Fatty acids profile (\% of total fatty acids) in the anterior gills of female E. sinensis subjected to different salinities for 40 days.

\begin{tabular}{|c|c|c|c|c|}
\hline \multirow[t]{2}{*}{ Fatty acids } & \multicolumn{4}{|c|}{ Salinity } \\
\hline & $0 \%$ & $6 \%$ & $12 \%$ & $18 \%$ \\
\hline C14:0 & $0.30 \pm 0.01^{b c}$ & $0.32 \pm 0.01^{b}$ & $0.44 \pm 0.02^{a}$ & $0.28 \pm 0.01^{c}$ \\
\hline C15:0 & $0.20 \pm 0.00^{b c}$ & $0.21 \pm 0.01^{b}$ & $0.27 \pm 0.02^{\mathrm{a}}$ & $0.17 \pm 0.00^{C}$ \\
\hline C16:0 & $11.22 \pm 0.06^{C}$ & $12.59 \pm 0.29^{b}$ & $15.49 \pm 0.54^{a}$ & $13.04 \pm 0.27^{b}$ \\
\hline C17:0 & $0.35 \pm 0.00^{b}$ & $0.31 \pm 0.01^{b}$ & $0.44 \pm 0.05^{a}$ & $0.28 \pm 0.01^{b}$ \\
\hline C18:0 & $7.14 \pm 0.13^{b c}$ & $6.71 \pm 0.15^{\mathrm{C}}$ & $8.58 \pm 0.13^{a}$ & $7.45 \pm 0.15^{b}$ \\
\hline C2O:0 & $0.72 \pm 0.00^{b}$ & $0.74 \pm 0.02^{b}$ & $0.92 \pm 0.04^{a}$ & $0.74 \pm 0.02^{b}$ \\
\hline C22:0 & $0.73 \pm 0.01^{b}$ & $0.84 \pm 0.02^{b}$ & $1.10 \pm 0.12^{a}$ & $0.86 \pm 0.02^{b}$ \\
\hline$\sum S F A$ & $20.67 \pm 0.20^{c}$ & $21.74 \pm 0.51^{b c}$ & $27.24 \pm 0.33^{a}$ & $22.81 \pm 0.47^{b}$ \\
\hline C16:1n7 & $2.91 \pm 0.02^{b}$ & $3.64 \pm 0.08^{a}$ & $3.85 \pm 0.18^{a}$ & $3.16 \pm 0.07^{b}$ \\
\hline C18:1n9 & $18.99 \pm 0.22$ & $19.93 \pm 0.46$ & $19.55 \pm 0.10$ & $19.47 \pm 0.40$ \\
\hline C18:1n7 & $3.12 \pm 0.04^{b}$ & $3.67 \pm 0.08^{a}$ & $3.23 \pm 0.03^{b}$ & $3.09 \pm 0.07^{b}$ \\
\hline C20:1n7 & $0.81 \pm 0.01^{b}$ & $0.87 \pm 0.02^{a}$ & $0.72 \pm 0.02^{\mathrm{C}}$ & $0.82 \pm 0.02^{a b}$ \\
\hline$\sum M U F A$ & $25.83 \pm 0.31^{b}$ & $28.13 \pm 0.65^{a}$ & $27.35 \pm 0.28^{a b}$ & $26.55 \pm 0.55^{a b}$ \\
\hline C18:2n6 & $7.02 \pm 0.03^{C}$ & $7.52 \pm 0.17^{a b}$ & $7.20 \pm 0.09^{b c}$ & $7.93 \pm 0.16^{a}$ \\
\hline C18:3n3 & $0.38 \pm 0.00^{b}$ & $0.44 \pm 0.01^{a}$ & $0.45 \pm 0.01^{a}$ & $0.40 \pm 0.01^{b}$ \\
\hline C20:2n6 & $2.30 \pm 0.04^{a}$ & $2.09 \pm 0.05^{b}$ & $1.79 \pm 0.09^{c}$ & $2.39 \pm 0.05^{a}$ \\
\hline C20:3n6 & $0.17 \pm 0.01^{b}$ & $0.20 \pm 0.00^{a b}$ & $0.08 \pm 0.03^{C}$ & $0.21 \pm 0.01^{a}$ \\
\hline C20:4n6 & $18.20 \pm 0.38^{b}$ & $18.58 \pm 0.43^{b}$ & $16.72 \pm 0.25^{\mathrm{C}}$ & $20.48 \pm 0.42^{a}$ \\
\hline C20:5n3 & $9.27 \pm 0.19^{a}$ & $8.22 \pm 0.19^{b}$ & $7.56 \pm 0.14^{C}$ & $7.07 \pm 0.15^{C}$ \\
\hline C22:6n3 & $4.78 \pm 0.10^{a b}$ & $5.00 \pm 0.11^{a}$ & $4.17 \pm 0.14^{\mathrm{C}}$ & $4.45 \pm 0.09^{b c}$ \\
\hline$\sum P U F A$ & $42.13 \pm 0.75^{a}$ & $42.04 \pm 0.97^{a}$ & $37.95 \pm 0.56^{b}$ & $42.92 \pm 0.88^{a}$ \\
\hline n-3PUFA & $14.43 \pm 0.29^{a}$ & $13.65 \pm 0.32^{a}$ & $12.18 \pm 0.28^{b}$ & $11.92 \pm 0.25^{b}$ \\
\hline n-6PUFA & $27.69 \pm 0.46^{b}$ & $28.39 \pm 0.66^{b}$ & $25.77 \pm 0.28^{c}$ & $31.01 \pm 0.64^{a}$ \\
\hline$n-3 / n-6$ & $0.52 \pm 0.00^{a}$ & $0.48 \pm 0.00^{b}$ & $0.47 \pm 0.01^{\mathrm{c}}$ & $0.38 \pm 0.00^{d}$ \\
\hline$\sum H U F A$ & $32.42 \pm 0.68^{a}$ & $31.99 \pm 0.74^{a}$ & $28.50 \pm 0.55^{b}$ & $32.21 \pm 0.66^{a}$ \\
\hline
\end{tabular}

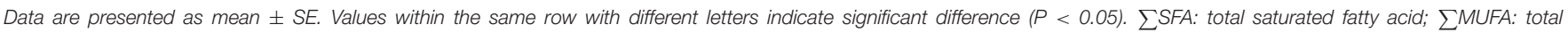
monounsaturated fatty acid; $\sum$ PUFA: total polyunsaturated fatty acid; $\sum H U F A$ : total highly unsaturated fatty acid. 
TABLE 4 | Fatty acids profile (\% of total fatty acids) in the posterior gills of female $E$. sinensis subjected to different salinities for 40 days.

\begin{tabular}{|c|c|c|c|c|}
\hline Fatty acids & \multicolumn{4}{|c|}{ Salinity } \\
\hline C15:0 & $0.15 \pm 0.00^{b}$ & $0.17 \pm 0.01^{a}$ & $0.18 \pm 0.00^{a}$ & $0.17 \pm 0.00^{a}$ \\
\hline C16:0 & $10.57 \pm 0.24^{d}$ & $14.03 \pm 0.33^{a}$ & $12.43 \pm 0.22^{b}$ & $11.52 \pm 0.27^{\mathrm{C}}$ \\
\hline C17:0 & $0.31 \pm 0.01^{b}$ & $0.34 \pm 0.01^{b}$ & $0.39 \pm 0.03^{a}$ & $0.32 \pm 0.01^{b}$ \\
\hline $\mathrm{C} 22: 0$ & $0.75 \pm 0.02^{b}$ & $0.73 \pm 0.02^{b}$ & $0.93 \pm 0.00^{\mathrm{a}}$ & $0.92 \pm 0.02^{\mathrm{a}}$ \\
\hline$\sum S F A$ & $19.47 \pm 0.45^{C}$ & $23.84 \pm 0.55^{\mathrm{a}}$ & $22.73 \pm 0.26^{a b}$ & $21.55 \pm 0.50^{b}$ \\
\hline C16:1n7 & $2.50 \pm 0.06^{d}$ & $3.75 \pm 0.09^{a}$ & $3.07 \pm 0.02^{b}$ & $2.83 \pm 0.07^{c}$ \\
\hline C18:1n9 & $17.92 \pm 0.41^{\mathrm{C}}$ & $20.76 \pm 0.48^{a}$ & $19.38 \pm 0.00^{b}$ & $19.68 \pm 0.46^{a b}$ \\
\hline C18:1n7 & $2.88 \pm 0.07^{C}$ & $3.36 \pm 0.08^{a}$ & $3.09 \pm 0.01^{b}$ & $3.03 \pm 0.07^{b c}$ \\
\hline C18:3n3 & $0.45 \pm 0.01^{b}$ & $0.48 \pm 0.01^{\mathrm{ab}}$ & $0.50 \pm 0.01^{\mathrm{a}}$ & $0.45 \pm 0.01^{b}$ \\
\hline C20:2n6 & $3.00 \pm 0.07^{a}$ & $2.55 \pm 0.06^{b}$ & $2.58 \pm 0.01^{b}$ & $2.49 \pm 0.06^{b}$ \\
\hline C20:3n6 & $0.15 \pm 0.00^{c}$ & $0.18 \pm 0.00^{b}$ & $0.19 \pm 0.00^{b}$ & $0.25 \pm 0.01^{a}$ \\
\hline C20:4n6 & $14.80 \pm 0.34^{C}$ & $15.63 \pm 0.36^{b c}$ & $16.67 \pm 0.04^{b}$ & $18.68 \pm 0.43^{a}$ \\
\hline C20:5n3 & $11.69 \pm 0.29^{a}$ & $8.85 \pm 0.20^{C}$ & $9.89 \pm 0.04^{b}$ & $8.91 \pm 0.21^{c}$ \\
\hline C22:6n3 & $4.35 \pm 0.10^{C}$ & $4.01 \pm 0.09^{d}$ & $4.68 \pm 0.02^{b}$ & $5.02 \pm 0.12^{a}$ \\
\hline$\sum$ PUFA & $42.34 \pm 0.98^{a b}$ & $40.55 \pm 0.93^{b}$ & $42.24 \pm 0.01^{\mathrm{ab}}$ & $44.03 \pm 1.02^{\mathrm{a}}$ \\
\hline n-3PUFA & $16.50 \pm 0.38^{a}$ & $13.34 \pm 0.31^{c}$ & $15.08 \pm 0.01^{b}$ & $14.38 \pm 0.33^{b}$ \\
\hline n-6PUFA & $25.84 \pm 0.60^{b}$ & $27.21 \pm 0.63^{b}$ & $27.16 \pm 0.00^{b}$ & $29.65 \pm 0.69^{a}$ \\
\hline$n-3 / n-6$ & $0.64 \pm 0.00^{\mathrm{a}}$ & $0.49 \pm 0.00^{c}$ & $0.56 \pm 0.00^{b}$ & $0.49 \pm 0.00^{c}$ \\
\hline
\end{tabular}

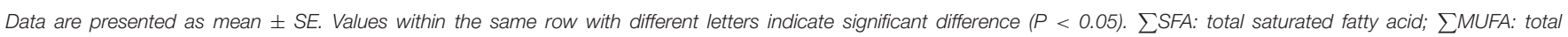
monounsaturated fatty acid; $\sum$ PUFA: total polyunsaturated fatty acid; $\sum$ HUFA: total highly unsaturated fatty acid.

hemolymph estrogen level, such as $17 \beta$-estradiol (E2), which activated/enhanced ovarian development (Wu and Jiang, 2001; Wei et al., 2007; Wu et al., 2013). On the other hand, HSI of the female E. sinensis showed an overall decreasing trend with increasing salinity, which is probably related to more hepatopancreas reserve being transferred to the ovaries under higher salinity conditions to facilitate ovarian development and maturation (Cheng et al., 1998; Teng et al., 2008).

It is worth noting that during the current experiment, egg carrying females were found in the two higher salinity treatments (12 and $18 \%$ ) despite no copulation had occurred as all crabs used were females. The observation that female crabs spawned without copulation was confirmed by checking spermathecaes of the ovigerous females under a microscope and no spermatophore was found in any of them. While spawning without copulation has not been reported previously for E. sinensis, in the giant freshwater prawn Macrobrachium rosenbergii, unmated ripe females have been reported to lay eggs within $24 \mathrm{~h}$ of pre-mating molt, but the unfertilised eggs drop off in 2-3 days (New et al., 2010); similar situation was also observed in the harlequin crab Lissocarcenus laevis (C. Zeng, personal observation). Similarly, in this study, all unfertilized eggs that initially attached to ovigerous crabs failed to develop further and eventually dropped off within a few days. It is likely that the favorable higher salinity conditions (12 and 18\%o) triggered rapid ovarian development that became irreversible, eventually led to unfertilized eggs being extruded by the females despite no copulation had happened. On the other hand, for those females kept in freshwater or low salinity conditions, oocyte development was much slower and probably were later re-absorbed as the external condition remained unfavorable.

Past studies reported clear differences in salinity of respective distribution areas of male and female E. sinensis in estuaries when they first arrived there for reproduction (Lai, 1994; Zhang and Li, 2002; Bentley, 2011). As such, there are likely gender differences in physiological responses to salinity changes, such as osmoregulation and metabolism. Gills play an important role in osmotic and ionic regulation in crustaceans (Mendonça et al., 2007; Romano and Zeng, 2010). Previous studies have demonstrated that the osmotic and ionic regulation in the posterior gills is dependent on ionic transport enzymes (e.g., $\mathrm{Na}^{+} / \mathrm{K}^{+}$-ATPase) and proteins (Kaplan, 2002; Henry et al., 2003). In this study, the activity of $\mathrm{Na}^{+} / \mathrm{K}^{+}$-ATPase in the posterior gills decreased significantly as salinity increased from 0 at $6 \%$ but increased with further increase in salinity with a significant higher activity recorded at $18 \%$. Such results 
TABLE 5 | Hemolymph metabolism indices of female E. sinensis subjected to different salinities for 40 days.

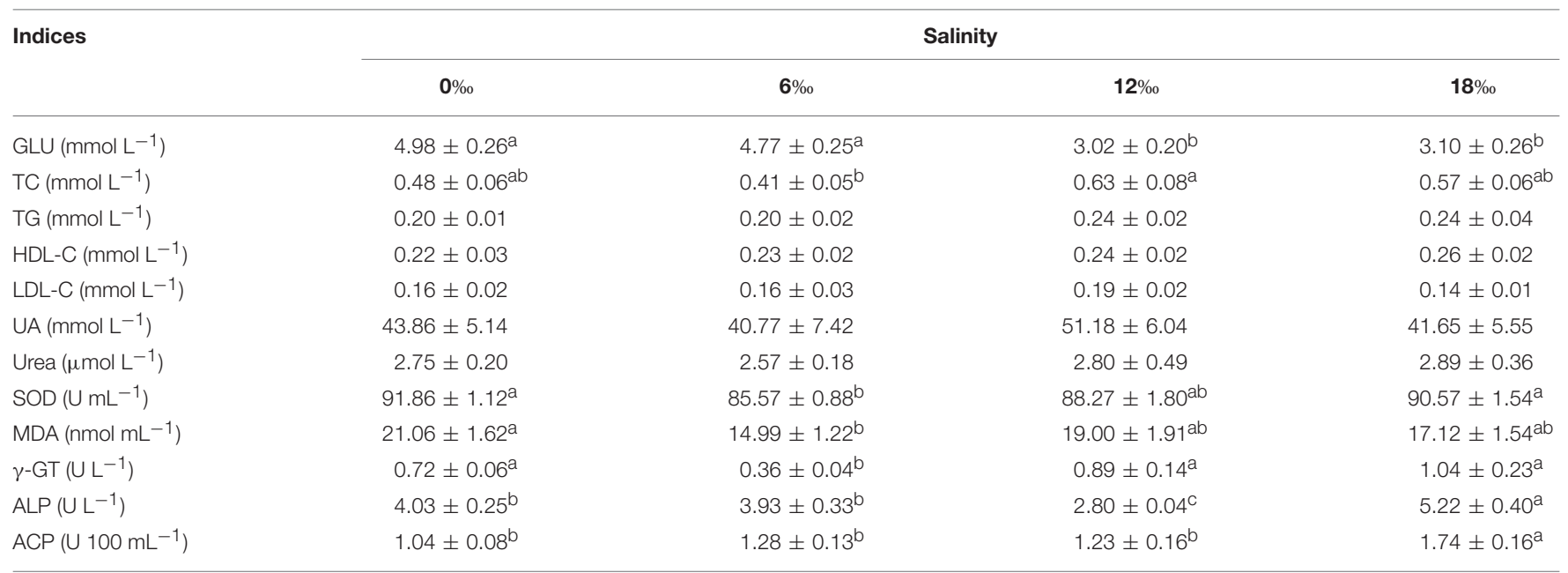

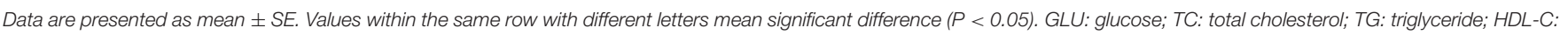

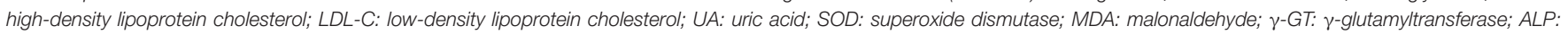
alkaline phosphatase; and ACP: acid phosphatase.

TABLE 6 | Hepatopancreas metabolism indices of female $E$. sinensis subjected to different salinities for 40 days.

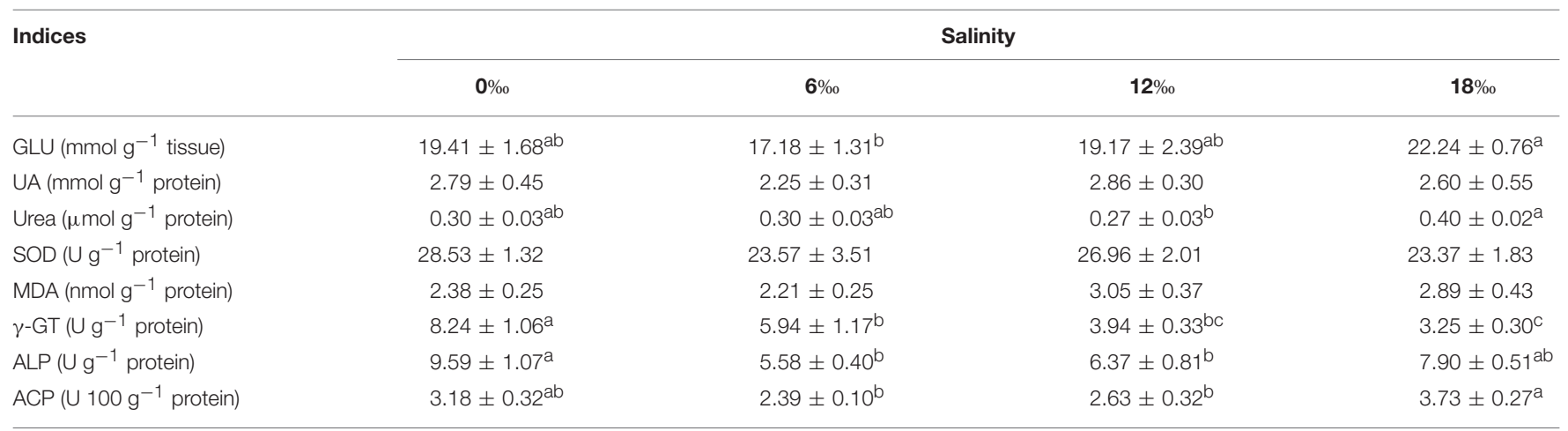

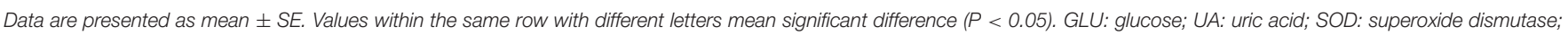
MDA: malonaldehyde; $\gamma$-GT: $\gamma$-glutamyltransferase; ALP: alkaline phosphatase; and ACP: acid phosphatase.

may be related to the changes in free amino acid contents in the hemolymph under different salinities. In addition to ions, free amino acids (FAAs) are also known to contribute to hemolymph osmolality and play an important role in osmoregulation in crustaceans (Kempf and Bremer, 1998; Huong et al., 2001). Our results showed that the most free amino acids and total amino acid (TFAAs) in hemolymph of the female crabs increased significantly to the highest levels as salinity increased from 0 to $6 \%$, it subsequently decreased as salinity increased further to $18 \%$. Such a trend differs from $\mathrm{Na}^{+} / \mathrm{K}^{+}$. ATPase activity in posterior gills which showed the lowest level at $6 \%$. The significantly higher TFAAs coincidental with the lowest gill $\mathrm{Na}^{+} / \mathrm{K}^{+}$-ATPase activity detected at $6 \%$ o suggests that compared to other salinity conditions, FFAs likely played a more significant role in osmoregulation at $6 \%$, which effectively reduced the need for ion transportation fueled by $\mathrm{Na}^{+} / \mathrm{K}^{+}$. ATPase. As the result, $\mathrm{Na}^{+} / \mathrm{K}^{+}$-ATPase activity level and energy expenditure by the female crabs on osmoregulation was reduced.
However, it is worth noting that a previous similar study by the author on male E. sinensis showed very different results, that the activity of $\mathrm{Na}^{+} / \mathrm{K}^{+}$-ATPase in the posterior decreased significantly with increasing water salinity (Long et al., 2017b). A possible explanation for such a gender difference in $\mathrm{Na}^{+} / \mathrm{K}^{+}$ATPase activity could be that for the female crabs subjected to higher salinities (12 and 18\%o), the rapid ovarian and oocyte development requires higher levels of certain irons, such as $\mathrm{Ca}^{2+}$, which is known to play an important role in regulating vitellogenesis in crustaceans (Paulus and Laufer, 1987; Quinito et al., 1989). To achieve that, $\mathrm{Na}^{+} / \mathrm{K}^{+}$-ATPase activity in the posterior gills of the female crabs subjected to higher salinities had to maintain at higher level than that of the males under similar salinity conditions.

Gill fatty acid profile can also reflect the physiological responses of crabs to environmental salinity changes (Lucu et al., 2008; Romano et al., 2014). The female E. sinensis subjected to higher salinity conditions were found to have higher total 
saturated fatty acids and total monounsaturated fatty acids in their anterior and posterior gills, similar results was reported for the amphipod Gammarus duebeni (Morris et al., 1982). This may be related to these fatty acids are the major energy source, hence their higher contents in the gills were linked to high energy requirements for respiration and osmoregulation in hypo-osmotic environment (Welcomme and Devos, 1991). Meanwhile, total polyunsaturated fatty acids and total highly unsaturated fatty acids in the posterior gills showed a trend of firstly decreased with increasing salinity (minimum detected at $6 \%$ ) but subsequently increased significantly as salinity increased further, which was consistent with the trend of $\mathrm{Na}^{+} / \mathrm{K}^{+}$-ATPase activity changes with salinity detected in the posterior gills. Such a pattern suggests that the membrane fluidity and $\mathrm{Na}^{+} / \mathrm{K}^{+}$ATPase activity in the posterior gills of female E. sinensis may be modulated by its fatty acid profile (Palacios et al., 2004).

The metabolism indices generally reflect the physiological status of E. sinensis exposed to different salinities (Jia et al., 2012; Feng et al., 2013). In this study, the contents of hemolymph glucose (GLU) in the female crabs subjected to higher salinity treatments of 12 and $18 \%$ were significantly lower than those from the low salinity treatments (0 and 6\%o). GLU is a major energy source for osmoregulation (Lorenzon et al., 1997; AlAzhary et al., 2008); since the osmolality of higher salinity waters (12 and 18\%o) were closer to the osmolality in the hemolymph when compared to the low salinities ( 0 and $6 \%$ ); fewer energy is expected to be required for osmoregulation by the crabs kept in salinity 12 and 18\%o (Jia et al., 2012), hence less GLU was produced. Meanwhile, cholesterol is not only a precursor of various hormones that regulate ovarian development and molt, but also an important component of cell membranes in crustaceans (Quackenbush, 1986; Cheng et al., 2000; Wei et al., 2005). In the current study, hemolymph total cholesterol level was the highest at 12 and $18 \%$, which may relate to accelerated ovarian development of the crabs under higher salinity conditions (Wu et al., 2013).

Urea is a metabolite of proteins, and its content generally reflects level of protein metabolism (Chen and Lin, 1995; Chang et al., 2007). In this study, the $18 \%$ o treatment resulted in the highest content of urea in the hepatopancreas, a similar result was reported for the Kuruma shrimp Marsupenaeus japonicus (Lee and Chen, 2003). Previous studies have shown that ammonia nitrogen could be converted to lower toxic urea, amino acids and other nitrogen compounds with elevated external salinities by crustaceans (Cheng and Chen, 1998; Lee and Chen, 2003), which may imply lower ammonia excretion of the female E. sinensis in high salinity waters.

Superoxide dismutase (SOD) is an important antioxidant enzyme that can scavenge free radicals and prevents tissue damages in crustaceans ( $\mathrm{Li}$ et al., 2008; Lu et al., 2011). The $6 \%$ salinity resulted in the lowest hemolymph SOD activity compared to other salinities, suggesting relatively lower level of free radicals in hemolymph of the female E. sinensis under the salinity (Chien et al., 2003; Wang et al., 2012). Meanwhile, malondialdehyde (MDA) is an indicator of lipid peroxidation, its content often reflects the levels of free radicals and cellular oxidation in tissues (Long et al., 2017a), both hemolymph and hepatopancrea MDA of the crabs were the lowest at $6 \%$ as compared to other salinities, again indicating lower peroxide stress in tissues at the salinity.

\section{CONCLUSIONS}

The present study demonstrated that brackish water accelerated ovarian development of female E. sinensis, in particular 12 and $18 \%$ salinities also led to unusual phenomenon of occurrence of ovigerous crabs without copulation, as well as generally lower levels of metabolism.

\section{ETHICS STATEMENT}

This study was conducted to investigate the effects of water salinity on gonadal development, osmoregulation and metabolism of adult female E. sinensis. The gonadal development situation of female crabs were checked via dissection, while the osmolality, major ions and free amino acids of hemolymph, gill $\mathrm{Na}^{+} / \mathrm{K}^{+}$-ATPase activity and its mRNA expression levels and fatty acids profile as well as the metabolism indices in hemolymph and hepatpancreas was analyzed with biochemical and molecular biology experimental methods. Prior to the sampling, all crabs will be treated with cold shock method to minimize suffering.

\section{AUTHOR CONTRIBUTIONS}

$\mathrm{XL}, \mathrm{XW}, \mathrm{CZ}$, and $\mathrm{YC}$ contributed to the conception and design of the work; XL, XW, and LZ contributed to data acquisition, analysis, and interpretation; XL, XW, CZ, HY, and YC drafted the work and revised it critically; XL, XW, LZ, HY, YC, and CZ agree to be accountable for all aspects of the work and ensure that questions related to the accuracy and integrity of all parts of the work are appropriately investigated and resolved.

\section{ACKNOWLEDGMENTS}

This study was supported by the two projects (13320502100 and 13231203504) from Shanghai Municipal Science and Technology Commission and the Scientific and Technological Cooperation Project (2014DFT30270) between Chinese mainland and Taiwan from Ministry of Science and Technology of China and a general project (No. 31572630) from the Natural Science Foundation. Infrastructure costs were supported by the Shanghai Universities First-class Disciplines project of fisheries (201562-0908) from Shanghai Municipal Education Committee, the extension project (2015-1-7) from Shanghai Agriculture Committee and the Capacity Promotion Projects (16DZ2281200, 13DZ2280500) of Shanghai Engineering and Technology Center from Shanghai Municipal Science and Technology Commission and the Special Fund (CARS-46) of Chinese Agriculture Research System-47 from Ministry of Agriculture of China. The authors would like thank the technical staff of Fengxian hatchery research center of Shanghai Fisheries Research Institute for their providing experimental tanks for this research. Most sincere thanks are also given to Lei $\mathrm{Xu}$, Hao Chen, and Wei Wang for their assistance with sampling and some biochemical analysis. 


\section{REFERENCES}

Al-Azhary, D. B., Tawfek, N. S., Meligi, N. M., and Elliottet, M. (2008). Physiological responses to hyper saline waters in Necora puber (Velvet Crab). Pak. J. Physiol. 4, 1-6.

Anger, K. (1991). Effects of temperature and salinity on the larval development of the Chinese mitten crab Eriocheir sinensis (Decapoda: Grapsidae). Mar. Ecol. Prog. Ser. 72, 103-110. doi: 10.3354/meps072103

Bentley, M. G. (2011). "The global spread of the Chinese mitten crab Eriocheir sinensis," in In the Wrong Place-Alien Marine Crustaceans: Distribution, Biology and Impacts, Invading Nature-Springer Series in Invasion Ecology, eds B. S. Galil, P. F. Clark, and J. T. Carlton (Dordrecht; Heidelberg; London; New York, NY: Springer), 107-127.

Chang, E. W. Y., Ai, M. L., Wong, W. P., Chew, S. F., Wilson, J. M., and Ip, Y. K. (2007). Changes in tissue free amino acid contents, branchial $\mathrm{Na}^{+} / \mathrm{K}^{+}$ATPase activity and bimodal breathing pattern in the fresh water climbing perch, Anabas testudineus (Bloch), during seawater acclimation. J. Exp. Zool. A Ecol. Genet. Physiol. 307, 708-723. doi: 10.1002/jez.a.424

Chen, J. C., and Lin, C. Y. (1995). Response of oxygen consumption, ammonia- $\mathrm{N}$ excretion and urea- $\mathrm{N}$ excretion of Penaeus chinensis exposed to ambient at different salinity and pH levels. Aquaculture 136, 243-255. doi: $10.1016 / 0044-8486(95) 01060-2$

Cheng, J. C., and Chen, J. C. (1998). Effects of nitrite exposure on the hemolymph electrolyte, respiratory protein and free amino acid levels and water content of Penaeus japonicas. Aquat. Toxicol. 44, 129-139. doi: 10.1016/S0166-445X(98)00064-2

Cheng, Y. X., Du, N. S., and Lai, W. (1998). Lipid composition in hepatopancreas of Chinese mitten crab Eriocheir sinensis at different stages. Acta Zool. Sinica $44,420-429$.

Cheng, Y. X., Wang, W., Wu, J. M., and Huang, X. Q. (2000). Lipid requirement of decapod crustacean larvae and the relationship between lipid and larval development. J. Fish. Sci. China 7, 104-107. doi: 10.3321/j.issn:1005-8737.2000.04.024

Cheng, Y. X., Wu, X. G., Yang, X. Z., and Hines, A. H. (2008). Current trends in hatchery techniques and stock enhancement for Chinese mitten crab, Eriocheir japonica sinensis. Rev. Fish. Sci. 16, 377-384. doi: 10.1080/10641260701681698

Chew, S. F., Ho, S. Y., and Ip, Y. K. (1999). Free amino acids and osmoregulation in the intertidal pulmonate Onchidium tumidium. Mar. Biol. 134, 735-741. doi: $10.1007 / \mathrm{s} 002270050590$

Chien, Y. H., Pan, C. H., and Hunter, H. (2003). The resistance to physical stresses by Penaeus monodon juveniles fed diets supplemented with astaxanthin. Aquaculture 216, 177-191. doi: 10.1016/S0044-8486(02)00056-X

Cieluch, U., Anger, K., Charmantier-Daures, M., and Charmantier, G. (2007). Osomoregulation and immuno localization of $\mathrm{Na}^{+} / \mathrm{K}^{+}$-ATPase during the ontogeny of the mitten crab Eriocheir sinensis (Decapoda, Grapsoidea). Mar. Ecol. Prog. Ser. 329, 169-178. doi: 10.3354/meps329169

Feng, G. P., Lu, J., Zhuang, P., and Wang, R. F. (2013). Effects of salinity on osmoionic regulation and enzyme activities in mature female Eriocheir sinensis. Mar. Fish. 35, 468-473. doi: 10.13233/j.cnki.mar.fish.2013.04.015

Folch, J., Lees, M., and Sloane-Stanley, G. H. (1957). A simple method for the isolation and purification of total lipides from animal tissues. J. Biol. Chem. 226, 497-509.

Genovese, G., Luchetti, C. G., and Luquet, C. M. (2004). $\mathrm{Na}^{+} / \mathrm{K}^{+}$-ATPase activity and gill ultrastructure in the hyper- hypo- regulating crab Chasmagnathus granulatus acclimated to dilute, normal and concentrated seawater. Mar. Biol. 144, 111-118. doi: 10.1007/s00227-003-1169-6

Guo, Z. H., Yang, Z. G., Cheng, Y. X., Ji, L. Y., Que, Y. Q., Liu, Z. W., et al. (2013). Molecular characterization, tissue expression of acyl-CoA $\Delta 9$-desaturaselike gene, and effects of dietary lipid levels on its expression in the hepatopancreas of the Chinese mitten crab (Eriocheir sinensis). Aquaculture 402-403, 58-65. doi: 10.1016/j.aquaculture.2013.03.033

Henry, R. P., Gehnrich, S., Weihrauch, D., and Towle, D. W. (2003). Salinitymediated carbonic anhydrase induction in the gills of the euryhaline green crab, Carcinus maenas. Comp. Biochem. Physiol. A Mol. Integr. Physiol. 136, 243-258. doi: 10.1016/S1095-6433(03)00113-2

Huong, D. T., Yang, W. J., Okuno, A., and Wilder, M. N. (2001). Changes in free amino acids in the hemolymph of giant freshwater prawn Macrobrachium rosenbergii exposed to varying salinities: relationship to osmoregulatory ability. Comp. Biochem. Physiol. A Mol. Integr. Physiol. 128, 317-326. doi: 10.1016/S1095-6433(00)00310-X

Jia, X. Y., Zhuang, P., Feng, G. P., Wang, R. F., Lu, J., and Huang, X. R. (2012). The relationship between hemolymph biochemical parameters and salinity in female parent Chinese mitten crab (Eriocheir sinensis). J. Fish. China 36, 91-97. doi: 10.3724/SP.J.1231.2012.27595

Kaplan, J. H. (2002). Biochemistry of Na, K-ATPase. Annu. Rev. Biochem. 71, 511-535. doi: 10.1146/annurev.biochem.71.102201.141218

Kempf, B., and Bremer, E. (1998). Uptake and synthesis of compatible solutes as microbial stress responses to high- osmolality environments. Arch. Microbiol. 170, 319-330. doi: 10.1007/s002030050649

Lai, W. (1994). The habits and reproductive migratory of Eriocheir sinensis. Fish World 6, 33-41.

Lee, W.-C, and Chen, J.-C. (2003). Hemolymph ammonia, urea and uric acid levels and nitrogenous excretion of Marsupenaeus japonicas at different salinity levels. J. Exp. Mar. Biol. Ecol. 288, 39-49. doi: 10.1016/S0022-0981(02)00597-X

Li, E. C., Chen, L. Q., Zeng, C., Yu, N., Xiong, Z. Q., Chen, X. F., et al. (2008). Comparison of digestive and antioxidant enzymes activities, hemolymph oxyhemocyanin contents and hepatopancreas histology of white shrimp, Litopenaeus vannamei, at various salinities. Aquaculture 274, 80-86. doi: 10.1016/j.aquaculture.2007.11.001

Long, X. W., Wu, X. G., Zhao, L., Liu, J. G., and Cheng, Y. X. (2017a). Effects of dietary supplementation with Haematococcus pluvialis cell powder on coloration, ovarian development and antioxidation capacity of adult female Chinese mitten crab, Eriocheir sinensis. Aquaculture 473, 545-553. doi: 10.1016/j.aquaculture.2017.03.010

Long, X., Wu, X., Zhao, L., Ye, H., Cheng, Y., and Zeng, C. (2017b). Effects of salinity on gonadal development, osmoregulation and metabolism of adult male Chinese mitten crab, Eriocheir sinensis. PLoS ONE 12:e0179036. doi: 10.1371/journal.pone. 0179036

Lorenzon, S., Giulianini, P. G., and Ferrero, E. A. (1997). Lipopolysaccharide induced hyperglycemia is mediated by $\mathrm{CHH}$ release in crustaceans. Gen. Comp. Endocr. 108, 395-405. doi: 10.1006/gcen.1997.6986

Lu, J., Zhuang, P., Feng, G. P., Zhang, L. Z., and Wang, R. F. (2011). Response of osmoregulation and antioxidation system to water salinity in parent Chinese mitten crab (Eriocheir sinensis). Mar. Fish. 33, 39-45. doi: 10.3969/j.issn.1004-2490.2011.01.007

Lucu, C., Pavičić, J., Ivanković, D., Pavičić-Hamer, D., and Najdek, M. (2008). Changes in $\mathrm{Na}^{+} / \mathrm{K}^{+}$-ATPase activity, unsaturated fatty acids and metallothioneins in gills of the shore crab Carcinus aestuarii after dilute seawater acclimation. Comp. Biochem. Physiol. A Mol. Integr. Physiol. 149, 362-372. doi: 10.1016/j.cbpa.2008.01.026

Mendonça, N. N., Masui, D. C., Mcnamara, J. C., Leone, F. A., and Furriel, R. P. M. (2007). Long-term exposure of the freshwater shrimp Macrobrachium olfersii to elevated salinity: effects on gill $\left(\mathrm{Na}^{+}, \mathrm{K}^{+}\right)$-ATPase $\alpha$-subunit expression and $\mathrm{K}^{+}$-phosphatase activity. Comp. Biochem. Physiol. A Mol. Integr. Physiol. 146, 534-543. doi: 10.1016/j.cbpa.2006.01.019

Morris, R. J., Lockwood, A. P. M., and Dawson, M. E. (1982). An effect of acclimation salinity on the fatty acid composition of the gill phospholipids and water flux of the amphipod crustacean Gammarus duebeni. Comp. Biochem. Physiol. A Physiol. 72, 497-503. doi: 10.1016/0300-9629(82)90114-1

Morrison, W. R., and Smith, L. M. (1964). Preparation of fatty acid methyl ester and dimethylacetals from lipids with boron trifluoride-methanol. J. Lipid. Res. $5,600-608$

New, M. B., Valenti, W. C., Tidwell, J. H., D’Abramo, L. R., and Nutty, M. N. (2010). Freshwater Prawn: Biology and Farming. Chichester: Willey-Blackwell.

Ohkawa, H., Ohishi, N., and Yagi, K. (1979). Assay for lipid peroxides in animal tissues by thiobarbituric acid reaction. Anal. Biochem. 95, 351-358. doi: 10.1016/0003-2697(79)90738-3

Palacios, E., Bonilla, A., Luna, D., and Racotta, I. S. (2004). Survival, $\mathrm{Na}^{+} / \mathrm{K}^{+}$ATPase and lipid responses to salinity challenge in fed and starved white pacific shrimp (Litopenaeus vannamei) postlarvae. Aquaculture 234, 497-511. doi: 10.1016/j.aquaculture.2003.12.001

Paulus, J. E., and Laufer, H. (1987). Vitellogenocytes in the hepatopancreas of Carcinus maenas and Libinia emarginata (Decapoda brachyura). Int. J. Invert. Reprod. Dev, 11, 29-44. doi: 10.1080/01688170.1987.10510265

Qiu, R. J., Cheng, Y. X., Huang, X. X., Wu, X. G., Yang, X. Z., and Tong, R. (2011). Effect of hypoxia on immunological, physiological response, and 
hepatopancreatic metabolism of juvenile Chinese mitten crab Eriocheir sinensis. Aquacult. Int. 19, 283-299. doi: 10.1007/s10499-010-9390-z

Quackenbush, L. S. (1986). Crustacean endocrinology: a review. Can. J. Fish. Aquat. Sci. 43, 2271-2282. doi: 10.1139/f86-278

Quinito, E. T., Hara, A., Yamauchi, K., Mizushima, T., and Fuji, A. (1989), Identification and characterization of vitellin in a hermaphrodite shrimp, Pandalus kessleri. Comp. Biochem. Physiol. B Comp. Biochem. 94, 445-451. doi: 10.1016/0305-0491(89)90179-X

Rathmayer, M., and Siebers, D. (2001). Ionic balance in the freshwateradapted Chinese crab, Eriocheir sinensis. J. Comp. Physiol. B. 171, 271-281. doi: 10.1007/s003600100173

Romano, N., Wu, X. G., Zeng, C. S., Genodepa, J., and Ellman, J. (2014). Growth, osmoregulatory responses and changes to the lipid and fatty acid composition of organs from the mud crab, Scylla serrata, over abroad salinity range. Mar. Biol. Res. 10, 460-471. doi: 10.1080/17451000.2013.819981

Romano, N., and Zeng, C. (2010). Survival, osmoregulation and ammonia-N excretion of blue swimmer crab, Portunus pelagicus, juveniles exposed to different ammonia-N and salinity combinations. Comp. Biochem. Physiol. C Toxicol. Pharmacol. 151, 222-228. doi: 10.1016/j.cbpc.2009.10.011

Romano, N., and Zeng, C. (2012). Osmoregulation in decapod crustaceans: a review on the mechanisms, implications to aquaculture productivity, methods for potential improvement and interactions with elevated ammonia exposure. Aquaculture 334-337, 12-23. doi: 10.1016/j.aquaculture.2011.12.035

Sui, L. Y., Zhang, F. M., Wang, X. M., Bossier, P., Sorgeloos, P., and Hänfling, B. (2009). Genetic diversity and population structure of the Chinese mitten crab Eriocheir sinensis in its native range. Mar. Biol. 156, 1573-1583. doi: 10.1007/s00227-009-1193-2

Teng, W. M., Cheng, Y. X., Wu, X. G., Yang, X. Z., Bian, W. J., Lu, Q. P., et al. (2008). A comparative study on some biological index changes concerned with gonad development between two population of the Chinese mitten crab (Eriocheir sinensis): Rhine and Yangze. J. Shanghai Fish. Univ. 17, 65-71.

Towle, D. W., and Weihrauch, D. (2001). Osmoregulation by gills of euryhaline crabs: molecular analysis of transporters. Am. Zool. 41, 770-780. doi: $10.1093 /$ icb/41.4.770

Wang, R. F., Zhuang, P., Feng, G. P., Zhang, L. Z., Huang, X. R., and Jia, X. Y. (2012). Osmotic and ionic regulation and $\mathrm{Na}^{+} / \mathrm{K}^{+}$-ATPase, carbonic anhydrase activities in mature Chinese mitten crab, Eriocheir sinensis H. Milne Edwards, 1853 (Decapoda, Brachyura) exposed to different salinities. Crustaceana 85, 1431-1447. doi: 10.1163/15685403-00003125

Wang, S. C., and $\mathrm{Xu}, \mathrm{L}$. (2003). Changes in hemolymph total protein and hemocyanin content of Eriocheir sinensis subjected different salinity. J. Huainan Teach. Coll. 5, 24-26. doi: 10.3969/j.issn.1009-9530.2003.03.010
Wei, W., Wei, H., and Liu, Q. (2005). Effect of estradiol in hemolymph and gonad on precociousness of Eriocheir sinensis. J. Fish. China 29, 862-865. doi: 10.3321/j.issn:1000-0615.2005.06.021

Wei, W., Wu, J. M., and Wei, H. (2007). Physiological mechanism of precociousness influenced by salinity in juvenile Eriocheir sinensis. J. Fish. Sci. China 14, 275-280. doi: 10.3321/j.issn:1005-8737.2007.02.015

Welcomme, L., and Devos, P. (1991). Energy consumption in the perfused gills of the euryhaline crab Eriocheir sinensis [H. Miln. Edw.] adapted to freshwater. J. Exp. Zool. 257, 150-159. doi: 10.1002/jez.1402570203

Wu, J. M., and Jiang, X. Y. (2001). The relationships between $\mathrm{Ca}^{2+}, 17 \beta$-estradiol levels in the hemolymph and precociousness of Eriocheir sinensis. J. Fish. China 25, 112-115. doi: 10.3321/j.issn:1000-615.2001.02.004

Wu, X. G., Zhao, Y. T., He, J., Huang, Q., Huang, Z. F., Liu, H., et al. (2013). Effect of brackish water and fresh water on gonadal development and mating behavior in adult Chinese mitten crab. Chin. J. Zool. 48, 99-105. doi: 10.13859/j.cjz.2013.04.008

Zeng, C., Cheng, Y., Lucas, J. S., and Southgate, P. C. (2012). "Other decapod crustaceans," in Aquaculture: Farming Aquatic Animals and Plants, 2nd Edn., eds J. S. Lucas and P. C. Southgate (Sussex: Blackwell Publishing), 514-539.

Zhang, L. S. (1973). The crabs life history research and juvenile crab fishing. Aquat. Sci. Technol. Intell. 1, 5-21. doi: 10.16446/j.cnki.1001-1994.1973.02.002

Zhang, L. S., and Li, J. (2002). Aquaculture Technology of Eriocheir sinensis. Beijing: Golden Shield Press.

Zhang, T. L., Li, Z. J., and Cui, Y. B. (2001). Survival, growth, sex ratio, and maturity of the Chinese mitten crab (Eriocheir sinensis) reared in a Chinese pond. J. Freshwater Ecol. 16, 633-640. doi: 10.1080/02705060.2001.9663855

Zhuang, P., Jia, X. Y., Feng, G. P., Zhang, L. Z., Wang, R. F., and Zhao, F. (2012). Variations of behavior and haemolymph physiology of female parent Chinese crab (Eriocheir sinensis) under different water salinities. Chin. J. Ecol. 31, 1997-2003. doi: 10.13292/j.1000-4890.2012.0245

Conflict of Interest Statement: The authors declare that the research was conducted in the absence of any commercial or financial relationships that could be construed as a potential conflict of interest.

Copyright (c) 2018 Long, Wu, Zhao, Ye, Cheng and Zeng. This is an open-access article distributed under the terms of the Creative Commons Attribution License (CC $B Y)$. The use, distribution or reproduction in other forums is permitted, provided the original author(s) or licensor are credited and that the original publication in this journal is cited, in accordance with accepted academic practice. No use, distribution or reproduction is permitted which does not comply with these terms. 